\title{
POTENTIAL OF TENDU LEAF REFUSE FOR PHENOL REMOVAL IN AQUEOUS SYSTEMS
}

\author{
G. K. NAGDA* - A. M. DIWAN - V. S. GHOLE \\ Department of Environmental Sciences, University of Pune, \\ Pune - 410007, India \\ (phone: +912172310145 ) \\ e-mail: gnagda@rediffmail.com \\ (Received $9^{\text {th }}$ January 2006; accepted $13^{\text {th }}$ May 2007)
}

\begin{abstract}
The potential of tendu (Diospyros melanoxylon) leaf refuse from bidi industry waste to remove phenol from aqueous solution was studied. For this purpose, the tendu leaf refuse was carbonized by subjecting it to chemical treatments with sulfuric acid. Batch kinetics and isotherm studies were carried out under varying experimental conditions of contact time, phenol concentration, adsorbent dose and $\mathrm{pH}$. Adsorption equilibrium of tendu leaf refuse and chemically carbonized tendu leaf refuse was reached within $2 \mathrm{hr}$ for phenol concentration 10-25 mg/l and $1 \mathrm{hr}$ for phenol concentration 20-200 mg/l, respectively. The adsorption of phenol decreases by the increase of the $\mathrm{pH}$ value of the solution. The kinetic data followed more closely the pseudo-second-order chemisorption model. The adsorption data were modelled by using both Langmuir and Freundlich classical adsorption isotherms. The maximum adsorption capacity of chemically carbonized tendu leaf refuse as per Langmuir model was 4 times higher than that of raw tendu leaf refuse. The results illustrate how tendu leaf refuse, a solid waste disposal menace from bidi industry, can be used as an effective biosorbent for phenol in aqueous solution. Keywords: Diospyros melanoxylon, biosorption, pseudo-second-order kinetics
\end{abstract}

\section{Introduction}

Pollution by phenols is an important environmental issue. Phenol, being a basic structural unit for a variety of synthetic organic compounds, wastewater originating from many chemical plants and pesticide and dye manufacturing industries contain this chemical. Wastewater from other industries such as paper and pulp, resin manufacturing, gas and coke manufacturing, tanning, textile, plastic, rubber, pharmaceutical, and petroleum also contain different types of phenols. Decay of vegetation also contributes phenols to water bodies. [1]. Phenols are considered as priority pollutants since they are harmful to organisms at low concentrations and many of them have been classified as hazardous pollutants because of their potential harm to human health [2]. The majority of phenols are toxic substances and some are known or suspected carcinogens [3]. It is important to remove phenols and aromatic compounds from contaminated industrial aqueous streams before discharged into any water body.

Conventional processes for removing phenolic compounds include extraction, adsorption on activated carbon; steam distillation, bacterial and chemical techniques, irradiation, etc. fail to generate final effluent with the required discharge quality at affordable costs [4]. Literature contains number of methods such as oxidation with ozone/hydrogen peroxide [5], ion exchange [6], electrochemical oxidation [7], reverse osmosis [8], photo-catalytic degradation [9], and adsorption [10] which have been used for the removal of phenols. The treatment of with active carbon, silicates and polymer resins are considered to be an effective method for the removal of phenol from wastewater because of its large surface area, micro-porous nature, high adsorption 
capacity, high purity and easy availability [11]. Phenol removal by adsorption process remains the best treatment of choice as it can generally remove all types of phenols in a simple and easy operation. The adsorbent that is used in practice remains activated carbon [12]. However because of high cost of activated carbon, its use is sometimes restricted on economical considerations. As such, attempts have been made by different workers to develop alternative adsorbents, preferably of low cost.

Literature survey shows that a large number of alternative adsorbents have been studied to replace activated carbon. Both, the industrial wastes as well as some natural resource materials such as bentonite [13], fly ash [14], spent bleaching earth [15], apricot stone shells [16], rubber seed coat [17], waste tire rubber [18], etc. have been utilized for this purpose. Recently interest has turned to using various biomasses and agricultural wastes as biosorbent, which have the advantage of low cost and increased tolerance of environmental conditions. Biosorption can be defined as a process in which solids of natural origin are employed for sequestration or separation of pollutants from an aqueous environment [19]. Many natural materials were used as biosorbent for phenol removal, like human hair [20] and chicken feather [21], chemically modified pistachio shells [22], Peanut Shell [23] and tamarind nutshell [24\} etc., presented with cheap viable options.

Tendu (Diospyros melanoxylon) leaf refuse, which itself is an environmental pollutant, generated during the manufacture of Indian crude cigarette bears this investigation. A bidi is smaller and less expensive than a cigarette and is considered a poor man's cigarette in India. Bidi is an indigenous crude cigarette in which tobacco is rolled in a small cut portion of tendu leaf and tied with a cotton thread. Tendu leaf is used as bidi wrapper on account of the ease with which it can be rolled and its wide availability. It also has agreeable flavor, resistance to decay and capacity to retain fires. Bidi rolling is a home industry covering thousands of homes in the industrial towns of Jabalpur and Solapur in India. This home industry of bidi making produces cuttings of tendu leaf as refuse which pollutes the dumping sites creating solid waste disposal problem of alarming scale. About 7200 tonnes of tendu leaf waste is generated per annum in the industrial town of Solapur, India [25]. Thus the aim of this work was to investigate the ability of tendu leaf refuse from bidi industry to remove phenol from aqueous solution and to determine its potential for use in the phenol removal from wastewater.

\section{Materials and methods}

\section{Preparation of biosorbent}

The tendu leaf refuse was obtained from the dumping sites near bidi industries in the town of Solapur, India. They were cut into small pieces of about 4-5mm, thoroughly washed with distilled water to remove all dirt, dried at $80^{\circ} \mathrm{C}$ till constant weight. The dried tendu leaf refuse (TLR) was powdered and sieved with an 80-mesh siever and stored in desiccator until used. Chemically modified carbon from tendu leaf refuse (TLR-CM) was prepared, by treating five part of TLR with three parts of concentrated sulfuric acid and kept in air tight oven at $150^{\circ}-160^{\circ} \mathrm{C}$ for 48 hours. The carbonized mass was washed free of acid with distilled water to get the $\mathrm{pH}$ 6.5. It was further filtered and dried at $110^{\circ} \mathrm{C}$ till constant weight. The material was pulverized and sieved through 150-mesh size and used as TLR-CM. (Table 1) gives the physical properties of thus prepared chemically carbonized tendu leaf refuse. 
Table 1. Physical parameters of chemically carbonized tendu leaf refuse.

\begin{tabular}{cc}
\hline Parameters & Characteristic value \\
\hline $\mathrm{pH}$ & 6.45 \\
Moisture $(\%)$ & 9.15 \\
Ash content $(\%)$ & 4.04 \\
Bulk density $(\mathrm{g} / \mathrm{ml})$ & 0.48 \\
Surface area $(\mathrm{m} 2 / \mathrm{g})$ & 210 \\
Pore volume $(\mathrm{ml} / \mathrm{g})$ & 0.13 \\
Iodine number & 128 \\
Cation exchange capacity (meq/g) & 1.02 \\
\hline
\end{tabular}

\section{Chemicals}

The test solutions were prepared by diluting of stock solution of phenol to the desired concentrations. A stock solution was obtained by dissolving $1.0 \mathrm{~g}$ of phenol, (obtained from Merck, India), in de-ionized water and diluted to $1000 \mathrm{ml}$. Desired solutions of phenol were prepared using appropriate subsequent dilutions of the stock solution. The range in concentrations of phenol prepared from standard solution varied between $10 \mathrm{mg} / \mathrm{l}$ to $200 \mathrm{mg} / \mathrm{l}$. Before mixing the adsorbent, the $\mathrm{pH}$ of each test solution was adjusted to the required value with diluted and concentrated sulfuric acid and sodium hydroxide solution, respectively. All $\mathrm{pH}$ measurements were carried out with a $\mathrm{pH}$ meter.

\section{Absorption studies}

Adsorption studies were performed in batch method; using $100 \mathrm{ml}$ aqueous phenol solutions of varying concentration in $250 \mathrm{ml}$ Erlenmeyer flasks and known amount of TLR and TLR-CM were added to each flask. The flasks were maintained at $30^{\circ} \mathrm{C}$ under constant stirring on a magnetic stirrer at $100 \mathrm{rpm}$. Samples were removed at different time intervals, centrifuged and analyzed for phenol. The uptake was calculated from the difference between the initial and final phenol concentration. Data for adsorption isotherm were obtained by allowing the adsorbents to remain in contact with the phenol solution for 24 hours. The phenol concentrations used were in the range of 20 to 200 ppm. All experiments were carried out in triplicates with respect to each condition and mean values were used for further calculations. The maximum deviation was $2.5 \%$.

\section{Analysis of phenol}

The concentration of phenol in the aqueous medium was determined with direct photometric method [26]. The absorbance of the coloured complex of phenol with 4aminoantipyrine was measured spectrophotometrically at $500 \mathrm{~nm}$. 


\section{Results and discussion}

The adsorption of phenol in aqueous solution on tendu leaf refuse (TLR) and chemically carbonized tendu leaf refused (TLR-CM) were examined by optimizing various physicochemical parameters such as; $\mathrm{pH}$, contact time, and the amount of adsorbent and adsorbate.

\section{Effect of pH on phenol removal}

In any adsorbate-adsorbent system, $\mathrm{pH}$ of the system affects the nature of surface charge of the adsorbent, effects ionization and the extent and rate of adsorption. Several $100 \mathrm{ml}$ portions of $100 \mathrm{mg} / \mathrm{l}$ of phenol solution were adjusted to assigned $\mathrm{pH}$ with sodium hydroxide or sulfuric acid and were mixed with different adsorbent doses with stirring for $1 \mathrm{~h}$. Measurement of initial and final phenol concentration gave the percent adsorption of phenol. The adsorption of phenol by TLR and TLR-CM was studied at various $\mathrm{pH}$ values as displayed in (Fig. 1.) Adsorbed amount decreased with increasing $\mathrm{pH}$ value, which can be attributed to the phenol ionization to form phenoate ions and at the same time the presence of hydroxyl ions on the adsorbent prevents the uptake of phenoate ions [27]. Similar behaviour has been reported during the adsorption of phenol onto bentonite [13]. Decrease in adsorbed phenol was sharp at $\mathrm{pH} 10$ in case of TLRCM.

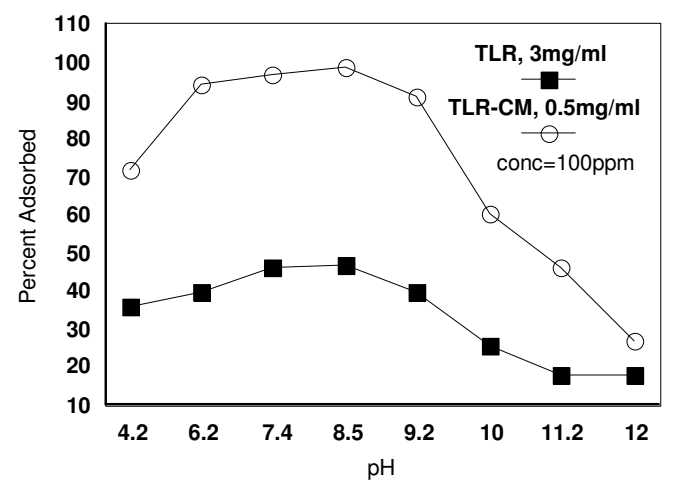

Figure 1. Effect of pH on phenol removal.

\section{Adsorption kinetics}

Phenol uptake by TLR and TLR-CM for different contact time were studied in batch experiments and shown in (Fig. 2) at different initial phenol concentration ranging from 10 to $200 \mathrm{ppm}$. The adsorbent mass used was $5 \mathrm{mg} / \mathrm{ml}$ for TLR and $1 \mathrm{mg} / \mathrm{ml}$ for TLR$\mathrm{CM}$ at $30^{\circ} \mathrm{C}$ ant at $\mathrm{pH}$ value of 7.2. The increase in initial phenol concentration results in an increase in the phenol uptake due to increase in mass transfer driving force resulting in higher phenol adsorption [12]. The results also showed that equilibrium time required for the adsorption of phenol on TLR and TLR-CM are $2 \mathrm{hr}$ and $1 \mathrm{hr}$ respectively, which is considered a relatively fast adsorption process. 

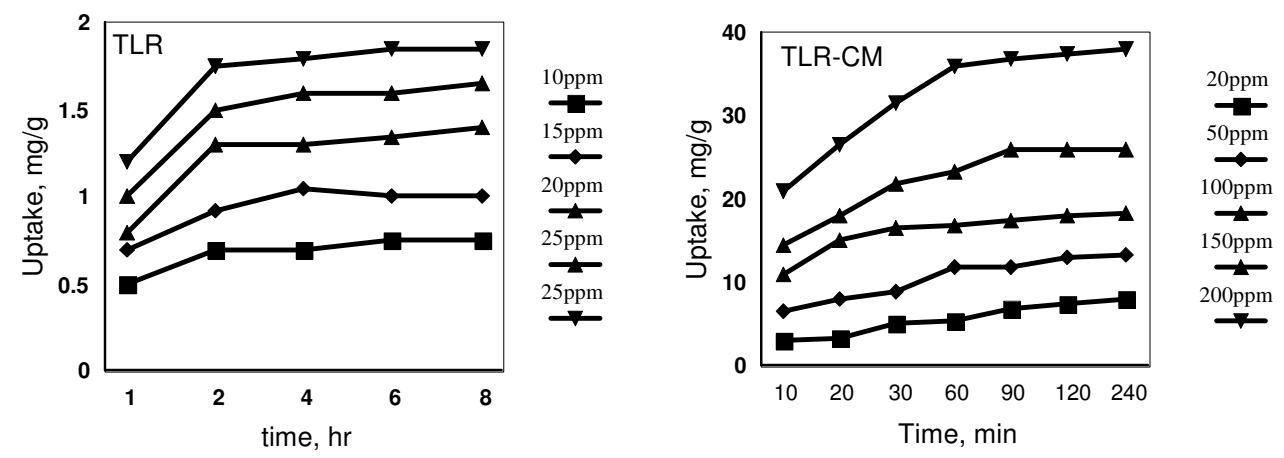

Figure 2. Kinetics of Phenol uptake at various initial concentrations of phenol by TLR and

TLR-CM.

The rapid adsorption of phenol onto the biosorbent, suggest that intra-particle diffusion is the limiting factor in this latter portion of the process. The kinetic data fits best in the Ho's pseudo-second-order chemisorption model [28] as shown in (Fig. 3).


Figure 3. Pseudo-second-order kinetics of phenol uptake by TLR and TLR-CM.

The pseudo-second order equation is based on the sorption capacity on the solid phase. It predicts the behaviour over the whole range of studies supporting a pseudosecond order equation and is in agreement with chemisorption being the rate-controlling step. The pseudo-second-order rate expression of Ho [28] has been applied widely to the sorption of metal ions, dyes, herbicides, oils and organic substances from aqueous systems.

\section{Effect of adsorbent concentration}

The effect of adsorbent concentration on phenol removal was studied where various amounts of TLR and TLR-CM were contacted with a fixed initial phenol concentration. The residual phenol was measured in the solution at equilibrium and results are shown in (Fig. 4.) The percentage of adsorption increases with the increase in adsorbent concentration as the number of adsorbent particles increases and more phenol is attached to their surface. 

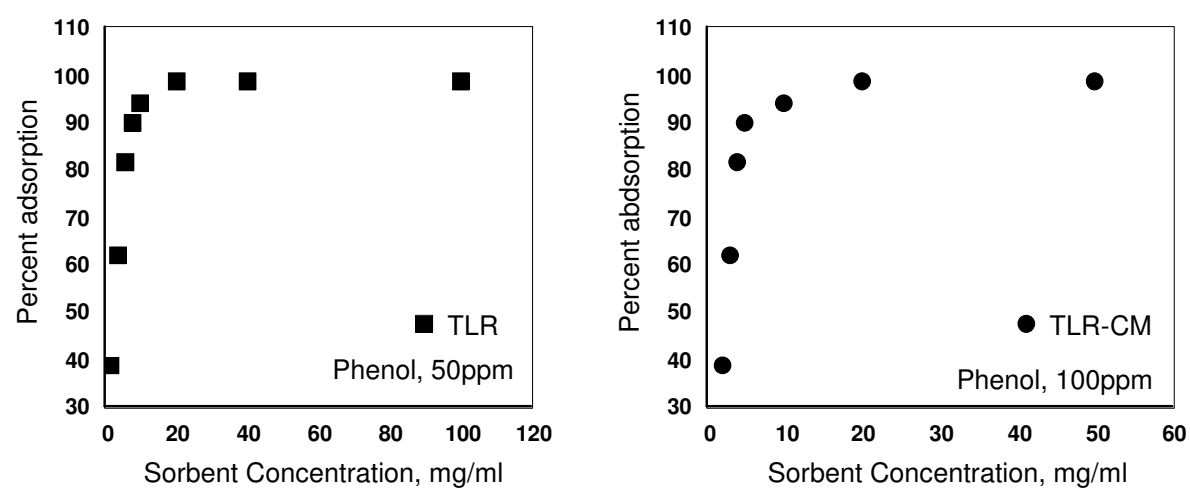

Figure 4. Effect of adsorbent concentration on phenol uptake by TLR and TLR-CM.

\section{Adsorption isotherms}

It essentially expresses the relation between the concentrations of the solute in solution at dynamic equilibrium with the concentration of the solute adsorbed onto the adsorbent at constant temperature. Several models have been published in the literature to describe experimental data of which the most common are the Langmuir isotherm and the Freundlich isotherm [29]. In order to facilitate the estimation of the adsorption capacities at various conditions, the Langmuir adsorption isotherm, a typical model for monolayer adsorption was applied. The linearized Langmuir model can be written as

$$
\frac{1}{Q_{e}}=\frac{1}{K_{L}}+\frac{1}{b K_{L}} \times \frac{1}{C_{e}}
$$

Where Ce is the concentration of phenol at equilibrium $(\mathrm{mg} / \mathrm{l}), \mathrm{q}_{\mathrm{e}}$ is the amount of phenol adsorbed at equilibrium $(\mathrm{mg} / \mathrm{g}), \mathrm{K}_{\mathrm{L}}(\mathrm{mg} / \mathrm{l})$ and $\mathrm{b}(\mathrm{mg} / \mathrm{g})$ are the Langmuir constants, representing the maximum adsorption capacity for the solid phase loading and the energy constant related to the heat of adsorption. The constants $b$ and $K_{L}$ can be evaluated from the intercept and slope of the linear plot of the experimental data of $1 / \mathrm{Qe}$ versus $1 / \mathrm{Ce}$, respectively.

The Freundlich isotherm has been widely adopted to characterize the adsorption capacity of organic pollutants using different adsorbents by fitting the adsorption data. The Freundlich isotherm in its linearized form can be written as:

$$
\log Q_{e}=\log K_{F}-\frac{1}{n} \times \log C_{e}
$$

Where, $\mathrm{K}_{\mathrm{F}}$ is a Freundlich constant related to the adsorption capacity $(\mathrm{mg} / \mathrm{g})$, and $1 / \mathrm{n}$ is the intensity of adsorption. The values of $\mathrm{K}_{\mathrm{F}}$ and $1 / n$ can be determined from the intercept and slope, respectively of linear plot of $\log$ qe versus $\log \mathrm{Ce}$.

The linearized Langmuir and Freundlich adsorption isotherms of TLR and TLR-CM for phenol are shown in (Fig. 5) and (Fig. 6) respectively. The Langmuir and Freundlich constants are displayed in (Table 2). 

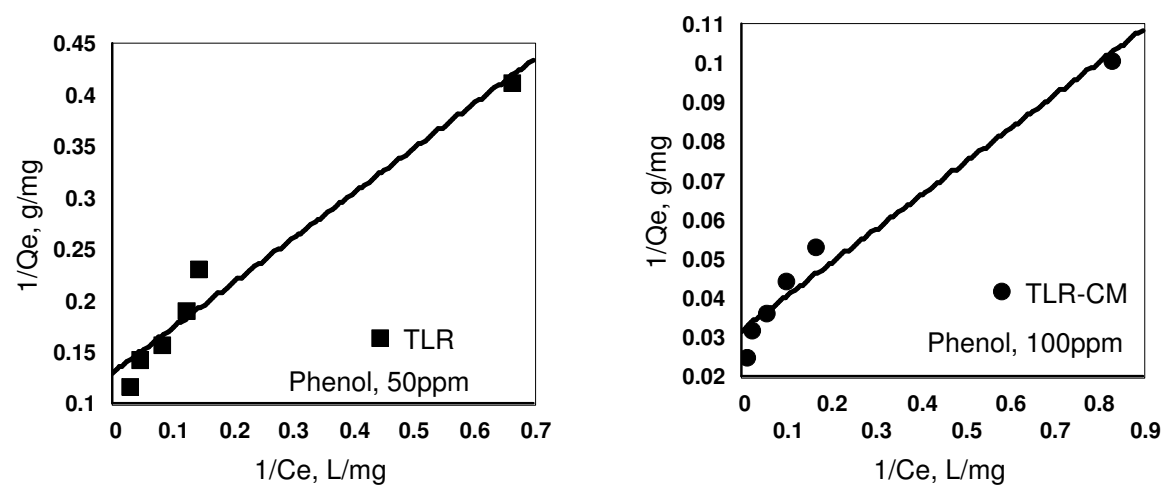

Figure 5. The linearized Langmuir Adsorption Isotherm for Phenol with TLR and TLR-CM.
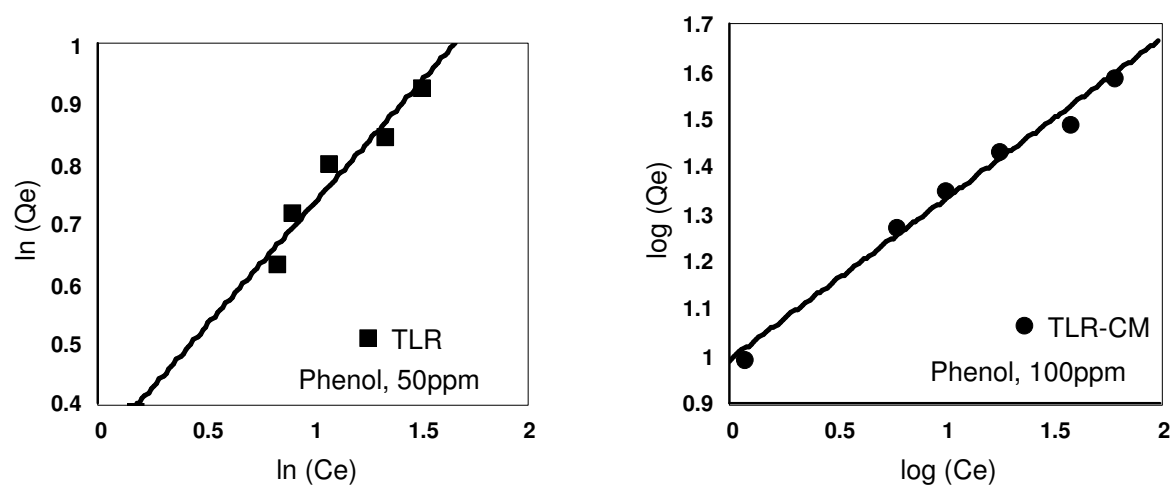

Figure 6. The linearized Freundlich Adsorption Isotherm for Phenol with TLR and TLR-CM.

Table 2. Adsorption isotherm parameters for the adsorption of phenol.

\begin{tabular}{c|cccccc} 
Adsorbent & Langmuir & \multicolumn{5}{c}{ Freundlich } \\
\hline & $\mathrm{K}_{\mathrm{L}},(\mathrm{mg} / \mathrm{g})$ & $\mathrm{b},(\mathrm{mg} / \mathrm{g})$ & $\mathrm{R}^{2}$ & $\mathrm{~K}_{\mathrm{F}}$ & $n$ & $\mathrm{R}^{2}$ \\
TLR & 0.299 & 7.6923 & 0.957 & 2.099 & 2.4631 & 0.977 \\
TLR-CM & 0.374 & 31.348 & 0.965 & 9.817 & 2.9586 & 0.986
\end{tabular}

The higher regression values showed that the equilibrium data for phenol fitted well to both the Langmuir and Freundlich isotherms in the studied concentration ranges. Based on the correlation coefficients $\left(\mathrm{R}^{2}\right)$, the equilibrium data was slightly better fitted in the Freundlich adsorption isotherm than the Langmuir equation (Table 2). The higher value of $\mathrm{K}_{\mathrm{F}}$, the Freunlich constant, showed easy uptake of phenol from aqueous solution [30]. Also the higher value of $n$ reflects the intensity of adsorption signifies that the surface of biosorbents is heterogeneous in nature and high enough for effective separation [31].

In this study, the ability of tendu leaf refuse from local bidi industry, which itself is a solid waste disposal menace and its chemically carbonized product to adsorb phenol was investigated. The equilibrium data were fitted well by the Freundlich and Langmuir isotherms where the data were slightly better fitted by the Freundlich isotherm in terms 
of regression values $\left(\mathrm{R}^{2}\right)$. The adsorption capacity increased four times after its carbonization with sulfuric acid. The pseudo-second-order chemical reaction kinetics of phenol adsorption on tendu leaf refuse provides the best correlation of the experimental data. On the bases of this study, it may be concluded that tendu leaf refuse-a pollution menace was found to be effective, efficient and promising adsorbent for phenol from aqueous solutions, providing attractive alternative for activated carbon.

Acknowledgements. Authors are grateful to Prof. R. K. Trivedy, Head, Department of Environmental Sciences, University of Pune, India, for providing laboratory facilities and encouragement and Prof. K. K. Pant, IIT-Delhi, for providing facilities for surface area and pore volume measurements.

\section{REFERENCES}

[1] Patterson, J. (1980): Waste Water Treatment Technology. - Ann Arbor Science Publishers, Ann Arbour, MI.

[2] U.S. Environmental Protection Agency (1987): Health and Environmental Effects Profile for Phenol. EPA/600/x-87/121. - Environmental Criteria and Assessment Office, Office of Health and Environmental Assessment, Office of Research and Development, Cincinnati, $\mathrm{OH}$.

[3] Verschueren, K. (1977): Handbook of Environmental Data on Organic Chemicals. - Van Nostrand Reinhold Co., New York.

[4] Nicell, J.A., Bewtra, J.K., Biswas, N., Taylor, E. (1993): Reactor Development for peroxidase catalyzed polymerazation and Precipitation of Phenols from Waste Water. Wat. Res. 27: 1629-1639

[5] Mokrini, A., Ousse, D., Esplugas, S. (1997): Oxidation of aromatic compounds with UV radiation/ozone/hydrogen peroxide. - Water Sci. Technol. 35: 95-102.

[6] Chan, W.C., Fu, T.P. (1998): Adsorption/ion-exchange behaviour between a waterinsoluble cationic starch and 2-chlorophenol in aqueous solutions. - J. Appl. Polym. Sci. 67: 1085-1092.

[7] Polcaro, A.M., Palmas, S. (1997): Electrochemical Oxidation of Chlorophenols - Ind. Eng. Chem. Res. 36 (5): 1791-1798.

[8] Goncharuk, V. V., Kucheruk, D. D., Kochkodan, V. M., Badekha, V. P. (2002): Removal of organic substances from aqueous solutions by reagent enhanced reverse osmosis. Desalination 143: 45-51.

[9] Koyama, O., Kamagat, Y., Nakamura K. (1994): Degradation of chlorinated aromatics by Fenton oxidation and methanogenic digester sludge. - Water Res. 28: 895-899.

[10] Danis, T. G., Albanis, T. A., Petrakis, D. E., Pomonis P. J. (1998): Removal of chlorinated phenols from aqueous solutions by adsorption on alumina pillared clays and mesoporous alumina aluminum phosphates - Water Res. 32: 295-302.

[11] Radeke, K.H., Loseh, D., Struve, K., Weiss E. (1993): Comparing adsorption of phenol from aqueous solution onto silica fangasite, activated carbon and polymeric resin. Zeolites 13: 69-70.

[12] Jung, M.W., Ahn, K.H., Lee, Y., Kim, K.P., Rhee, J.S., Tae Park, J.,, Paeng, K.J. (2001): Adsorption characteristics of phenol and chlorophenols on granular activated carbons (GAC). - Microchemical Journal 70: 123-131.

[13] Banat, F.A., Al-Bashir, B., Al-Asheh, S., Hayajneh O. (2000): Adsorption of phenol by bentonite. - Environ Pollution 107: 391-398.

[14] Singh, B.K., Nayak, P.S. (2004): Sorption Equilibrium Studies of Toxic Nitro-substituted Phenols on Fly Ash. - Adsorption Science and Technology 22: 295-309. 
[15] Pollard, S.J.T., Sollars, C.J., Perry, R. (1991): A low cost adsorbent from spent bleaching earth. I. The selection of an activation procedure. - J. Chem. Technol. Biotechnol. 50: 265-275.

[16] Daifullah, A.A.M., Girgis, B.S. (1998): Removal of some substituted phenols by activated carbon obtained from agricultural waste. - Water Res. 32: 1169-1177.

[17] Rengaraj, S., Moon S., Sivabalan, R., Arabindoo, B., Murugesan, V. J. (2002): Removal of phenol from aqueous solution and resin manufacturing industry wastewater using an agricultural waste: rubber seed coat. - J. Jazard. Mater. 89: 185-196.

[18] San Miguel, G, Fowler, G.D., Sollars, C.J. (2002): Adsorption of organic compounds from solution by activated carbons produced from waste tyre rubber. - Sep. Sci. Technol. 37: 663-676.

[19] Muraleedharan, T.R., Iyenger, L., Venkobachar, C. (1991): Biosorption - an attractive alternative for metal removal and recovery. - Curr. Sci. 61: 379-384.

[20] Banat, F.A., Al-Asheh, S. (2001): The Use of Human Hair Waste as a Phenol Biosorbent. -Adsorption Science and Technology 19: 599-608.

[21] Banat, F.A., Al-Asheh S. (2001): The Use of Columns Packed with Chicken Feathers for the Removal of Phenol from Aqueous Solutions. - Adsorption Science and Technology 19: $553-563$

[22] Attia, A.A., Girgis, B.S., Khedr, S.A., (2003): Capacity of activated carbon derived from pistachio shells by H3PO4 in the removal of dyes and phenolics. - J. Chem. Technol. Biotechnol. 78: 611-619.

[23] Gonzo, E.E., Gonzo, L.F. (2005): Kinetics of Phenol Removal from Aqueous Solution by Adsorption onto Peanut Shell Acid-activated Carbon. - Adsorption Science and Technology 23: 289-302

[24] Goud, V.V., Mohanty, K., Rao, M.S., Jayakumar N.S. (2005): Phenol Removal from Aqueous Solutions by Tamarind Nutshell Activated Carbon: Batch and Column Studies. - Chem Eng. \& Tech. 28: 814-821.

[25] Kadam, D.G. (2004): Studies on vermicomposting of tendu leaf (Diospyros melanoxylon Roxb.) refuse with emphasis on microbiological and biochemical aspects. - Ph.D. thesis, Shivaji University, Kolhapur, India. pp 14-20

[26] APHA, AWWA, WEF. (1995): Standard methods for the examination of water and wastewater. - 19th Edn. Washington.

[27] Halouli, K.A., Drawish, N.M., (1995): Effects of $\mathrm{pH}$ and inorganic salts on the adsorption of phenol from aqueous systems on activated decolourising charcoal. - Sep. Sci. Technol. 30: 3313-24.

[28] Ho, Y.S., Wase, D.A.J., Forster, C.F. (1996): Kinetic studies of competitive heavy metal adsorption by sphagnum moss peat, - Environ. Technol. 17: 71-77.

[29] Casey, T.J. (1997): Unit Treatment Processes in Water and Wastewater Engineering. John Wiley and Sons Ltd, England, pp 113-114.

[30] Rengaraj, S., M. Seuny-Hyeon,, Sivabalan, R. (2002): Agricultural solid waste for the removal of organics: adsorption of phenol from water and wastewater by Palm seed coat activated carbon. - Waste Management 22: 543-548.

[31] Khalid, N., Ahmad S., Toheed, A., Ahmad, J. (2000): potential of rice husks for antimony removal. - Applied Radiation and Isotopes 52: 30-38. 